\title{
A pontomedullary lesion of aberrant pyramidal tract with ipsilateral central facial paresis
}

\author{
Kiyotaka Nakamagoe, Kazuhiro Ishii, Masahiko Watanabe, Akira Tamaoka \\ Department of Neurology, Institute of Clinical Medicine, University of Tsukuba,Tsukuba, Japan
}

Correspondence to Kiyotaka Nakamagoe, Nakamagoek@md.tsukuba.ac.jp

\section{DESCRIPTION}

The patient, a 76-year-old man, developed central facial paresis on the left side (figure 1). Eleven days after the onset of his symptoms, MRI showed a faint area of signal hyperintensity in the left dorsal pontomedullary junction on T1-weighted imaging along with an area of signal hypointensity in the interior of the brainstem and an area of signal hyperintensity in the margin on $\mathrm{T} 2$-weighted imaging (figure $2 \mathrm{~A}-\mathrm{C}$ ). After 2 months, facial paresis disappeared almost completely and the lesion was smaller (figure 2D). Based on these MRI findings, ipsilateral central facial paresis resulting from a microhaemorrhage at a cavernous angioma was diagnosed.

A unilateral lesion of the ventromedial brainstem generally exhibits a clinical picture of crossed paresis consisting of central facial paresis contralateral to the lesion. ${ }^{1}$ On the other hand, with a unilateral lesion of the dorsolateral brainstem concurrent ipsilateral central facial paresis has been reported. ${ }^{1}$ Some facial corticobulbar tract fibres are thought to leave the corticospinal tract at the pontomedullary junction as an aberrant pyramidal tract. ${ }^{1-3}$ Most of the fibres of the aberrant pyramidal tract descend to the level of the ventromedial upper medulla and then decussate and ascend in the dorsolateral medulla to reach the contralateral facial nucleus of the lower pons. ${ }^{1}{ }^{2}$ Our dorsolateral lesion was thought to be affecting the ascending fibres of the aberrant pyramidal tract after their decussation causing ipsilateral facial paresia. Ipsilateral central facial weakness with pontomedullary lesions is due to the ascending fibres of the aberrant pyramidal tract.

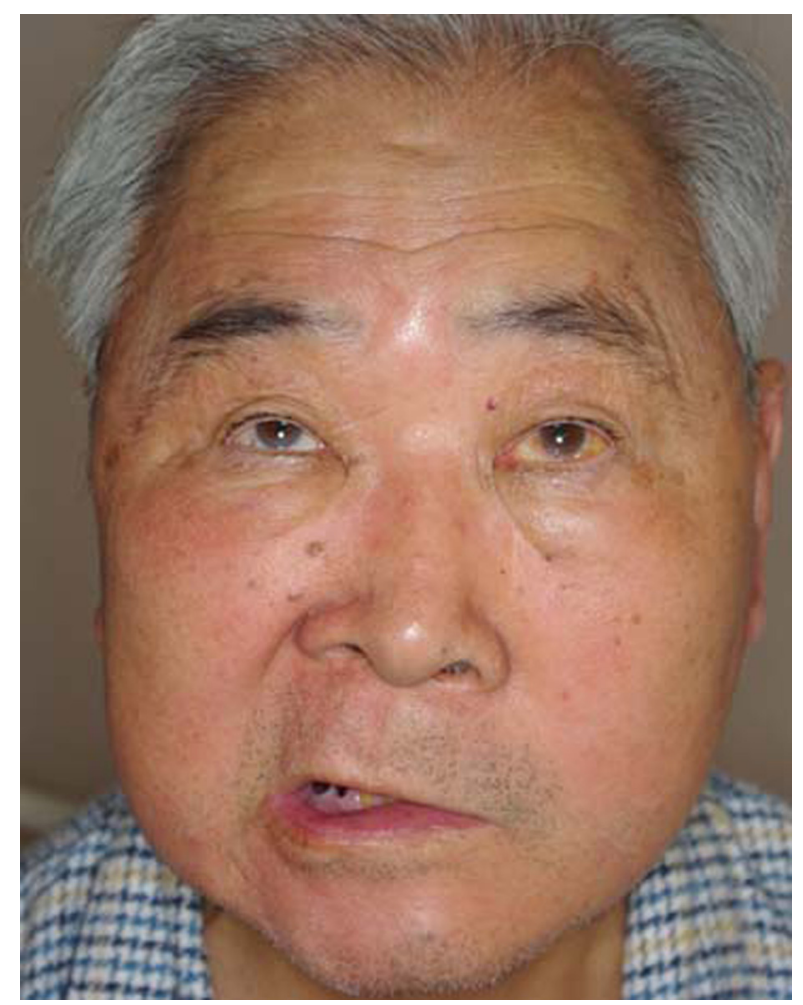

Figure 1 The patient was lucid with no bilateral differences in forehead wrinkling. However, muscular weakness was observed in the left orbicularis oculi and orbicularis oris muscles. 


\section{BMJ Case Reports}

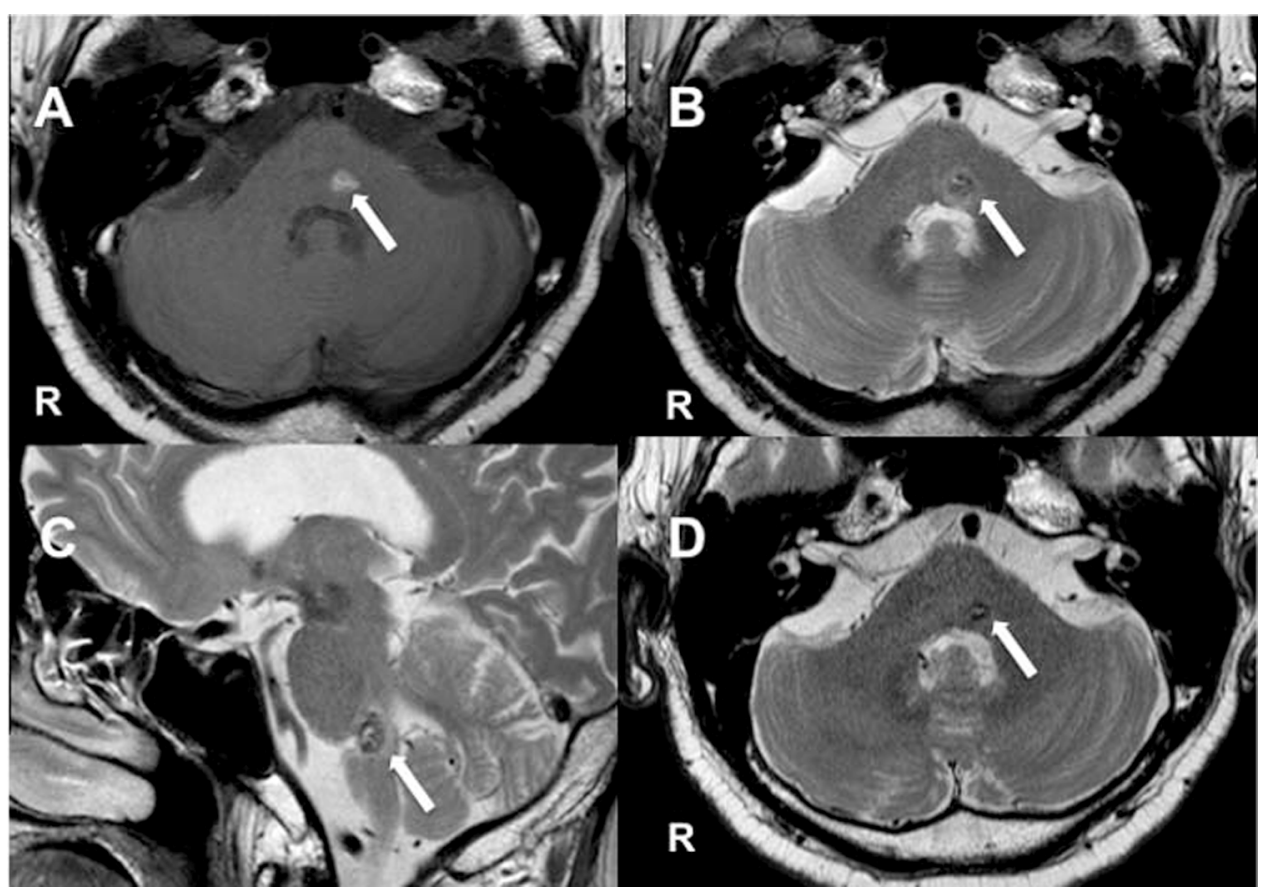

Figure 2 An axial T1-weighted image (A), an axial T2-weighted image (B) and a mid-sagittal T2-weighted image (C) show signal changes and swelling (arrows) at the pontomedullary junction. (D) An axial T2-weighted image shows a reduced lesion (arrow) 2 months after the onset of symptoms.

Acknowledgements The authors thank Dr Akinori Sugaya and Dr Ayako Shioya (Department of Neurology, University of Tsukuba, Institute of Clinical Medicine) for the treatment of the patient.

\section{Competing interests None.}

Patient consent Obtained.

\section{REFERENCES}

1. Terao S, Miura N, Takeda A, et al. Course and distribution of facia corticobulbar tract fibres in the lower brain stem. J Neurol Neurosurg Psychiatr 2000;69:262-5.

2. Currier RD. The medial medullary syndrome. J Univ Mich Med Cent1976;42:96-104.

3. Yamamoto T, Yamasaki M, Imai T. Retrograde pyramidal tract degeneration in a patient with cervical haematomyelia. J Neurol Neurosurg Psychiatr 1989;52:382-6.

This pdf has been created automatically from the final edited text and images.

Copyright 2010 BMJ Publishing Group. All rights reserved. For permission to reuse any of this content visit http://group.bmj.com/group/rights-licensing/permissions.

BMJ Case Report Fellows may re-use this article for personal use and teaching without any further permission.

Please cite this article as follows (you will need to access the article online to obtain the date of publication).

Nakamagoe K, Ishii K, Watanabe M, Tamaoka A. A pontomedullary lesion of aberrant pyramidal tract with ipsilateral central facial paresis. BMJ Case Reports 2010;10.1136/bcr.05.2010.3003, date of publication

Become a Fellow of BMJ Case Reports today and you can:

- Submit as many cases as you like

- Enjoy fast sympathetic peer review and rapid publication of accepted articles

- Access all the published articles

- Re-use any of the published material for personal use and teaching without further permission

For information on Institutional Fellowships contact consortiasales@bmjgroup.com

Visit casereports.bmj.com for more articles like this and to become a Fellow 